\title{
LAS CAPILLAS DEL CANÓNIGO FRANCISCO DE MADRID EN LA CUIDAD DE BAZA (GRANADA)
}

\author{
JUAN MANUEL SEGURA FERRER \\ Universidad de Granada.
}

\author{
CÉSAR VALERO SEGURA \\ Universidad de Granada.
}

\begin{abstract}
Resumen
En las décadas de los años treinta y ochenta del quinientos se levantaron las dos capillas donde fue enterrado el canónigo Francisco de Madrid, uno de los más destacados miembros de la élite eclesiástica de la Baza del siglo XVI. En un primer momento sus restos mortales fueron depositados, de forma temporal, en una de las capillas más relevantes de la girola de la iglesia colegial de Santa María. A finales de la década de los ochenta se levantaba la capilla definitiva en la iglesia conventual de Santa Isabel de los Ángeles.
\end{abstract}

\section{Palabras claves}

Baza. Arquitectura. Siglo XVI. Canónigo Francisco de Madrid. Covarrubias, Gibaja, Luis Antón, Jusepe Díaz.

\section{THE CHAPELS OF THE CANON FRANCISCO DE MADRID IN THE CITY OF BAZA (GRANADA)}

\section{Abstract}

In the decades of the thirties and eighties of the five hundred the two chapels were erected where the canon Francisco de Madrid was buried, one of the most outstanding members of the ecclesiastical elite of the Baza of the sixteenth century. At first, his mortal remains were deposited, temporarily, in one of the most important chapels of the church of Santa Maria. In the late eighties the final chapel stood in the convent church of Santa Isabel de los Angeles.

\section{Keywords}

Baza. Architecture. Century XVI. Canon Francisco de Madrid. Covarrubias, Gibaja, Luis Antón, Jusepe Díaz. 


\section{Introducción}

El canónigo Francisco de Madrid, integrante de uno de los linajes más influyentes de la Baza del quinientos, fue enterrado en dos capillas desconocidas hasta la actualidad. Aunque la historiografía actual aporta algunos datos a cerca de dicho señor nada dice sobre estas edificaciones y sus emplazamientos. El prelado fue enterrado de forma provisional en una de las capillas de la girola de la iglesia colegial de Santa María, la del Santísimo Sacramento, levantada en 1534 y adquirida por el comitente en 1552. A finales de la década de los ochenta, viendo que no se iba a construir el convento que mandaba fundar, en cuya capilla mayor quería ser enterrado, sus albaceas deciden desviar el capital de su herencia para fundar cuatro plazas de monjas pobres y levantar la capilla definitiva en el convento de Santa Isabel de los Ângeles.

Antes de comenzar el estudio de estas dos construcciones vamos a dar una serie de pinceladas biográficas sobre el papel social (político, económico...) y familiar del comitente, sabiendo con antelación que siempre habrá aspectos de su vida que quedarán en la sombra. Creemos importante profundizar en su papel religioso con su intento fallido de fundar un convento, paso previo a la construcción a la capilla que finalmente recogerá sus restos mortales.

\section{El comitente}

El origen del linaje de los Madrid de Baza está ligado a la Reconquista de urbe y a sus primeros pobladores. Procedía esta familia de la ciudad Toledo, en el Reino de Castilla. En el horizonte de los integrantes de este linaje estuvo el conseguir cargos de relevancia en la jerarquía civil y eclesiástica bastetana, ocupándolos desde el último tercio del siglo XV y durante todo el XVI.

No existe hoy en día un estudio que aborde la personalidad y la trayectoria del canónigo y ganadero Francisco de Madrid pero han aparecido publicadas algunas referencias en diversos artículos relacionados con la ciudad, que junto a los datos dispersos que aportamos, nos permiten disponer de material para reconstruir algunos aspectos destacados de su biografía y, sobre todo, del papel que jugó en la Baza del siglo XVI uno de los personajes más importantes de la parroquia de Santa María. Futuras investigaciones ayudaran a fijar un perfil más detallado del comitente. Hemos estado indagando en la ciudad del quinientos y hemos localizado varios datos relevantes sobre este personaje y su familia.

El canónigo era hijo de Juan de Madrid, caballero y guarda de los Reyes Católicos en el momento de la Reconquista, siendo el primer mayordomo de los propios de la urbe. Dicho cargo tuvo en los siglos XV y XVI una gran importancia e influencia en los gobiernos locales y ofrecía la posibilidad de escalar posiciones en la esfera social y política. Según el historiador Javier Castillo dicho señor formó parte del elenco de "hombres horrados " que colaboraron como consejeros en diversos asuntos importantes del cabildo en el inicio de la ciudad cristiana ${ }^{1}$. En cuanto al desempeño de destacados cargos a nivel civil de otros miembros de su familia señalar a su hermano Diego, escribano del concejo y regidor de la ciudad. Fue recibido como escribano el 19 de septiembre de 1494.

Los datos más relevantes localizados sobre la trayectoria del canónigo Francisco de Madrid están relacionados con su labor religiosa y con su recorrido como "señor del ganado". En cuanto a su formación académica y su función dentro de la iglesia bastetana no es mucho lo que hoy conocemos, señalando su participación en la demanda interpuesta en 1511, junto a otros miembros del cabildo abacial, contra los beneficiados de las villas de Zújar y Caniles y contra Alonso Pérez de Hellín ${ }^{2}$. El resto de la información localizada a nivel religioso está relacionada con la compra de la capilla de la iglesia colegial dónde pidió ser enterrado y con su proyecto fallido de levantar un convento de religiosas en la ciudad, hechos que detallaremos más adelante.

\footnotetext{
${ }^{1}$ Castillo Fernández, 2005: 30-31.

${ }^{2}$ Crespo Muñoz, 2007: 533.
} 
Francisco formaba parte de una familia de posición económica acomodada. Debió educarse en un ambiente eminentemente religioso, recibiendo de sus progenitores unas sólidas creencias que habrían de tener un peso importante en su vida. Desconocemos cuando tomó posesión de sus funciones como canónigo en la parroquia de Santa María de la Encarnación de Baza. Lo que sí está documentado es que en 1511 ya ocupaba dicho cargo. El canónigo era el eclesiástico que tenía un cargo relevante y disfrutaba de una prebenda o canonjía en una iglesia catedral o colegial. Los integrantes de la jerarquía eclesiástica, entre los que estaban los canónigos, solía llevar una vida más desahogada que el resto del clero y sus ocupaciones le permitían dedicarse a todo tipo de aficiones y negocios que, en muchos casos, poco tenía que ver con su vocación religiosa.

La labor de nuestro comitente en el mundo de la ganadería ha dejado más rastros documentales que su trayectoria religiosa. Según el profesor Francisco Tristán el canónigo fue el más importante ganadero de la ciudad ${ }^{3}$. Desconocemos cuando comenzó su andadura en esta rama de la economía, una de las más prosperas en el siglo XVI.

La ganadería y sus derivados fue uno de los campos económicos en los que despuntó la urbe en el quinientos. Según cálculos del historiador Tristán García, entre una quinta y una sexta parte de la población cristianovieja se dedicaba al sector ganadero o a sus industrias derivadas. En una coyuntura económica favorable, con creciente demanda y elevación de precios de la lana y la carne, muchos integrantes de la élite local, tanto a nivel civil como religioso, se implicaron en este negocio, colaborando en muchas ocasiones, en el aprovisionamiento de las carnicerías y en la compra/venta de lana.

Creemos que el canónigo comenzó su actividad ganadera en los años veinte, pues en la década anterior no existen registros en protocolos notariales que lo relacionen con la explotación ganadera. El despegue de su andadura en esta rama de la economía parece coincidir con el momento el que se hace el Repartimiento de tierras en la sierra bastetana (1525), lugar adecuado para dedicarlo a nuevos cultivos y a pastos para el ganado. Tras la crisis demográfica de principios de la década de los años veinte en el reino granadino, provocada por una epidemia de peste y una carestía de trigo, el ayuntamiento solicitó a la corona el reparto entre los vecinos de la sierra de Baza, que tras la conquista, había quedado como tierra comunal ${ }^{4}$. Cómo a los demás canónigos de la ciudad, en el reparto le correspondieron tres peonías o una caballería y media.

Para la alimentación de su extensa ganadería necesitaba arrendar amplios terrenos con pastos abundantes en distintas comarcas de Andalucía Oriental y del Sudeste. Como señala el historiador Julián Pablo Díaz a mediados de siglo destacaba como uno los ganaderos más importantes del Reino de Granada, arrendando varios ejidos completos, caso del Alxibe Quebrado ${ }^{5}$.

Para llevar a cabo la dirección y control de su ganadería, y más teniendo en cuenta que había que dedicar gran parte de su tiempo a su labor religiosa, disponía de un mayoral, un pastor principal encargado de dirigir a una o varias cuadrillas, ejerciendo dichas funciones, en los años cincuenta, Alonso de Espinar.

En los desplazamientos de los ganados por las sierras hubo ciertos momentos en los que se tuvieron que firmar acuerdos entre agricultores y ganaderos, como el 27 de octubre de 1551, en el que el mayoral del canónigo había acordado que cuando pasase con su ganado, por ciertos lugares, tenía que controlar que esté no dañase las plantaciones de cereales, viñedos y arbolado (olivares) ${ }^{6}$.

\footnotetext{
3 Tristán García, 1999: 147.

4 Tras la confección de un padrón de cristianos viejos que, -en teoría- serían los únicos que podrían participar, el repartimiento de la Sierra de Baza se efectuó entre 1524 y 1525.

${ }^{5}$ Díaz López, 1998: 245-246.

${ }^{6}$ Bernard, 1998: 219-220. Asimismo se concibe el que se tomen precauciones al encuentro de las piaras de cerdos que, según escritura del 3 de noviembre de 1551 "no han de entrar en lo llano ni ejidos salvo en todos los otros baldíos después de idos los herbajeros" y que, según otra "con que puede beber el agua de las fuentes e ríos fuera de ejidos".
} 
Al ser uno de los mayores propietarios de ganado se convirtió también en uno de los más destacados abastecedores de las carnicerías de la ciudad, por ejemplo el 3 de octubre de 1524 y el 10 de abril de 1525 proporcionaba 300 y 200 carneros respectivamente para el suministro local ${ }^{7}$.

El volumen de capital que acumuló con los ingresos de su oficio, las rentas eclesiásticas, y su labor de gran ganadero, le hizo poseedor de un importante caudal, motivo por el cual pensó dedicar gran parte de dicho patrimonio a fundar y levantar un monasterio para monjas. Casi todos los conventos de la ciudad eran de órdenes masculinas. Sólo existió una comunidad de religiosas hasta el siglo XVIII, la de Santa Isabel de los Ángeles, fundación de los Enríquez-Luna, a la que iban a parar las integrantes de la élite bastetana y de las poblaciones de su área de influencia.

Según las autoridades eclesiásticas, la dotación que quedó tras el fallecimiento del canónigo para el establecimiento de un convento fue insuficiente para poder levantarlo y mantenerlo tan sólo con las rentas que producía el patrimonio legado, motivo por el cual la fundación quedó suspendida y las rentas de la misma se desviaron al convento de Santa Isabel de los Ángeles, con la dotación de cuatro plazas para monjas de origen humilde y con la construcción de una capilla en honor al patrocinador.

\section{Testamento}

Francisco de Madrid otorgaba testamento cerrado y sellado el 17 de julio de 1563 ante el escribano Diego del Puerto ${ }^{8}$. Deseaba que su cuerpo fuese depositado temporalmente en la capilla de la iglesia colegial que había adquirido en la década de los años cincuenta. Desde allí habría de pasar a la capilla mayor del convento de monjas que mandaba fundar y levantar en la ciudad. Nombraba como patrón al abad y cabildo y designaba como primer capellán a su sobrino Francisco de Figueroa.

A quién mas favoreció en su testamento fue al género femenino, tanto a las mujeres con las que convivió (hermanas, sobrinas y criadas) como a las futuras monjas, de origen humilde, del convento que mandaba fundar tras su fallecimiento. En primer lugar se preocupó de dejar asegurado el futuro de sus hermanas solteras, Luisa y Francisca, legándoles 100 ducados y los usufructos de una hacienda en el pago de Jabalcón y de su casa principal, sita en la plaza de Santa María, donde residía. En los bajos de dicha vivienda había una tienda, cuyas rentas les aportarían unos buenos ingresos anuales.

Tras la muerte de los progenitores, sus hermanas debieron irse a vivir con el comitente. Su presencia en la residencia del canónigo obedece a la solidaridad y protección familiar, revistiendo un carácter de reprocidad, al trabajar en muchos casos para los clérigos. Era habitual que las mujeres solteras se cobijasen en casa de parientes colaterales, si habían fallecido sus padres. Además, de hacerles compañía, su presencia solía tener una estrecha relación con el servicio doméstico. Debieron ejercer la función de amas de llaves, dedicándose al gobierno de la casa y coordinación el trabajo de las criadas en las labores de limpieza, mantenimiento, cocina, etc. Las amas eran las personas en quién depositaban su entera confianza, a las que se sentían muy apegados, en muchos casos por estar unidos familiarmente.

Otra de las beneficiadas en su testamento fue Catalina Cordoncillo, hija de María de Figueroa, su sobrina, 200 ducados de dote para contraer matrimonio o para ingresar como monja en un convento. Si se casase y no tuviese hijos, especificaba en su testamento que dicho caudal no lo heredase su padre ni persona de su linaje, sino que fuese a pasar al monasterio que ordenaba fundar. En último lugar mencionar a Luisa y Elvira, hijas de Pedro de Segura, a las que dejaba en herencia 12.000 maravedíes como dote para su casamiento.

\footnotetext{
7TTistán García, 1999: 404-405.

8 Testamento del canónigo Francisco de la Madrid, 17 de julio de 1563, Archivo de Protocolos de Granada (A.P.Gr.), Baza, Diego del Puerto, ff. 338-347.
} 
También fueron favorecidas las integrantes de la servidumbre, legándole 2.000 maravedíes a cada una de las mozas que estuvieran sirviendo en su casa en el momento de su fallecimiento, pagando así su soldada (servicios prestados) junto a una aportación extra que les ayudase a contar con cierto caudal para que pudieran contar con una dote con la que poder contraer matrimonio.

\section{Fundación fallida de un convento}

El gran montante de su patrimonio iba dirigido a doncellas pobres y con vocación religiosa. En la Edad Moderna la mujer, desde que nacía, era preparada para cumplir sus funciones en el ámbito doméstico y en el ejercicio de la maternidad. Aquellas que no contraían matrimonio o no entraban en un convento corrían el riesgo de finalizar sus días solas y en completo estado de abandono. Para tratar de ayudar a las mujeres desprotegidas y con vocación, el canónigo las beneficiaba dándoles la oportunidad de acceder al convento que ordenaba fundar si aportación de una dote, pues el coste de la misma se hacía misión imposible para muchísimas familias, más si eran huérfanas o hijas de viudas pobres.

En su testamento dejaba estipulado su principal objetivo, fundar y levantar un convento de la orden de Santa Clara, que habría de llamarse de Nuestra Señora de la Concepción, estando la iglesia del mismo bajo la advocación de Santa Ana, fundación que nunca llego a realizarse. En la capilla mayor del futuro templo de este recinto monacal sólo podrían enterrarse el comitente, sus hermanas y sus deudos.

Ordenaba que tras su fallecimiento se habían de vender la mayoría de sus propiedades, incluida su importantísima cabaña ganadera (junto con los asnos, burros y perros vinculados a la misma), una huerta en el pago de Bernal Francés y todos sus bienes muebles y semovientes, exceptuando las alhajas y ropa de su casa, utilizando el caudal resultante a pagar sus deudas y a fundar censos con cuyas rentas llevar a cabo lo marcado en su testamento: comprar el solar donde edificar el cenobio, levantarlo y labrarlo sin que faltase de nada. Cuando estuviese el edificio a punto de ser habitado, y antes de que entrasen las monjas a ocuparlo, las rentas que produjeran los censos de un año se dedicarían a amueblar el templo y a dotarlo de todo lo necesario para el culto divino, incluidos los cálices y demás objetos litúrgicos. Los ingresos de su hacienda de Jabalcón, 100 ducados anuales, se destinarían para el mantenimiento del convento.

Las monjas habrían de ser originarias de la ciudad e ingresarían sin dote. Debían ser horradas, honestas, virtuosas y de buenas formas. Para la selección e ingreso de las aspirantes nombraba a sus hermanas en un primer lugar, y fallecidas éstas, la elección se realizaría por parte del abad y cabildo abacial, el guardián del convento de San Francisco y el prior del monasterio de San Jerónimo.

Favorecer a las órdenes femeninas por parte de las altas dignidades eclesiásticas fue habitual en toda la Edad Moderna, fundando conventos, levantado capillas e instaurando capellanías en los templos de dichos cenobios, caso de los presbíteros Juan Linares y Benito de Quesada en el convento de Santa Isabel de los Ángeles.

\section{La capilla temporal del canónigo en la iglesia colegial}

Tras la conquista de la ciudad en 1489 la mezquita principal se convirtió en iglesia colegial. Hasta 1528 no se tomó el acuerdo para levantar un templo de nueva planta bajo un diseño gótico, con capilla mayor, trascoro y posiblemente tres naves. La obra se remató en 1529 con el maestro Pedro de Urrutia por 800.000 maravedíes. Durante los dos primeros 


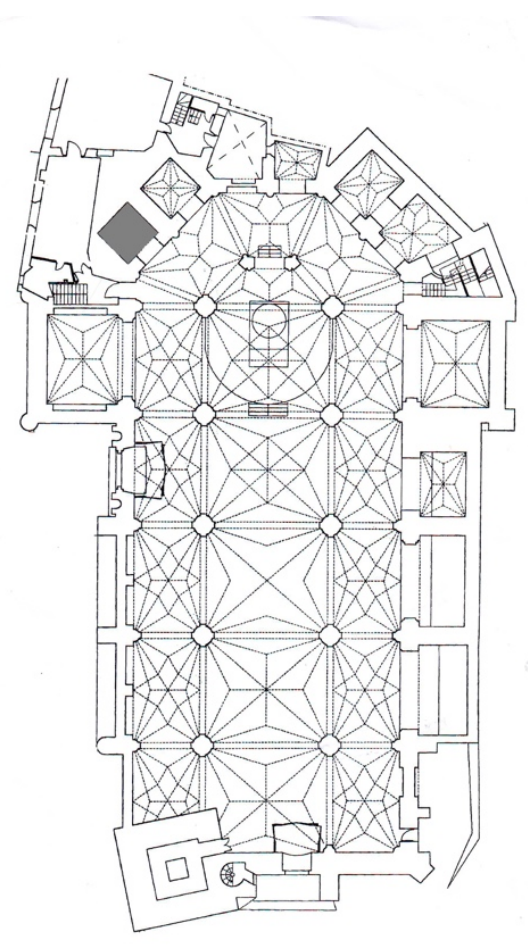

Fig. 1. Planta de la iglesia de Santa María de la Encarnación.

años la construcción se centró en la cabecera pero el terremoto de septiembre de 1531 derrumbó gran parte de la obra recién levantada.

Para realizar las trazas del edificio definitivo se pensó en Alonso de Covarrubias "uno de los mejores maestros de traza e obra de cantería". El arquitecto castellano había sido llamado por la iglesia local pues la Abadía bastetana estuvo vinculada a la archidiócesis de Toledo hasta 1544, año en el que se firmó la Concordia de Valladolid, pasando, a partir de ese momento a depender de forma definitiva del obispado de Guadix.

El maestro propuso derribar lo que aún se conservaba en buen estado, siendo favorable a la eliminación de la girola para dar más amplitud a la capilla mayor. Los comitentes no aceptaron la propuesta de la supresión de la girola sino que obligaron a respetar los cimientos levantados, condicionando la traza de Covarrubias. La obra se contrató en 1534 con Rodrigo de Gibaja, quién debió respetar lo que quedaba en pie y bien conservado, especificando en el contrato los pilares entorchados del proyecto anterior, los cuales habían de levantarse hasta el arranque de las bóvedas.

Tradicionalmente la arquitectura gótica de las grandes catedrales, e iglesias colegiales, abría en las girolas capillas de dimensiones reducidas cubiertas con sencillas bóvedas, adaptadas al espacio entre contrafuertes, destinadas a ser panteones de eclesiásticos prominentes y destacados miembros de la élite religiosa y civil. Según Camón Aznar, la distribución pareada de estas capillas estaría inspirada en la catedral de Murcia, por la similar disposición, esquema que también se seguiría en la coetánea colegiata de San Patricio de Lorca (Murcia).

Aunque la mayoría de los historiadores consideran que las capillas abiertas a la girola son anteriores al terremoto de 1531, no es así. Se construyeron, como el resto del templo, tras el gran seísmo. En 1534, y posiblemente el año siguiente, se levantaba la capilla del 
Santísimo Sacramento, la de nuestro comitente, construcción identificada y descrita por primera vez en este artículo?.

Sobre la imagen tardogótica de esta parte del templo se han pronunciado varios especialistas, caso de la profesora Soledad Lázaro, al señalar que los arcos apuntados y sistema de abovedamiento de estas capillas evidencian la utilización de un vocabulario formal y estructural enraizado en el último Gótico ${ }^{10}$. En 1897 Gómez Moreno apuntaba que todas presentan un tipología muy similar, el mismo tipo de portada (menos la última) y bóvedas de crucería apoyadas en ménsulas ${ }^{11}$. El ilustre historiador intuía que todas ellas las levantó el mismo arquitecto y eso indica la documentación que hemos localizado.

Es de suponer que el proyecto de la girola, y de las capillas asomadas a la misma, se hizo dentro del espíritu del diseño de los años veinte. Otro elemento que debe acercarse al diseño anterior al terremoto, alejándose de la traza de Covarrubias, son los arcos apuntados de las portadas de dichas capillas, en contraposición con los arcos de medio punto utilizados en el resto del templo.

Centraremos nuestra atención en la capilla de Francisco de Madrid, una de las construcciones privadas más destacadas de la girola, ofreciendo en la actualidad un pálido reflejo de su primitiva magnificencia al haber desaparecido todo su patrimonio mueble tras las distintas vicisitudes sufridas a lo largo de la historia: retablo, pinturas y objetos litúrgicos. A finales del siglo XVI, o en la primera mitad del XVII, la propiedad de dicha capilla pasó a la familia de los Méndez Pardo, a quién perteneció durante toda la Edad Moderna.

\section{La capilla del Santísimo Sacramento pasa a ser propiedad del canónigo}

El flanco de levante de la girola debió conservar, tras el terremoto, parte de los muros en buen estado, los que el cabildo quiso mantener en la definitiva construcción. Las obras del nuevo templo, y las del flanco de poniente de la girola, especialmente las de esta capilla, llamada del Santísimo Sacramento, se iniciaron en la primavera de 1534. Para finales de ese año se había levantado el arco "con todo lo demás que sobre dicho arco y alrededor de el está agora edificado"12. Tras su construcción debió convertirse en la sede del Santísimo Sacramento hasta que fue vendida a nuestro comitente.

Deseoso nuestro canónigo de disponer de un panteón temporal para su enterramiento decidió comprar una de las capillas de la girola construidas por la Abadía, al igual que hicieron otras altas dignidades eclesiásticas de este periodo. El 31 de marzo de 1552 Francisco de Madrid se quedaba con la propiedad. Tasaron la construcción los maestros de cantería Rodrigo de Gibaja y Martín de Alzaga. El canónigo se comprometía a pagar el coste de la misma en cuatro plazos. La capilla fue valorada en 94.580 maravedíes, detallándose en el contrato de compra el valor de todos los elementos que la configuraban, comenzando por los cimientos (14.280), siguiendo por los muros (45.000) y terminando por la bóveda, en la que se incluían las pechinas, los nervios de la crucería, el ladrillo y el enlucido, 27.800 maravedíes. A todo se le añadían $7.500^{13}$. El comprador se comprometía a fundar una capellanía con una renta anual de 10.000 maravedíes al año para su mantenimiento, con la obligación de mantener la lámpara del Santísimo Sacramento siempre encendida.

\footnotetext{
9 Probablemente se mantenía en buen estado de conservación, además de los cimientos y arranques de la girola, parte de los muros de algunas capillas asomadas a la misma y las bases de las portadas, motivo por el cual se respetaría el diseño tardogótico ya marcado en el contrato con el fallecido Pedro Urrutia. No era necesario diseñar de nuevo dichas capillas pues la traza de finales de la década de los años veinte se adaptaba perfectamente al espacio existente.

${ }^{10}$ Lázaro Damas, 2003: 511-524.

11 Descripción de la iglesia colegial por el historiador Manuel Gómez. Moreno, Instituto Gómez Moreno (I.G.M.), Legajo CXXVII, no 2138.

12 LÁZARO DAMAS, 2003: 518. Dicha historiadora no localiza esta capilla.

13 Contrato de compra de la capilla del Santísimo Sacramento por parte del canónigo Francisco de Madrid, A.P.Gr., Baza, Diego del Puerto, 1552, ff. 1317-1318.
} 
Fig. 2. Portada de la capilla temporal del canónigo.

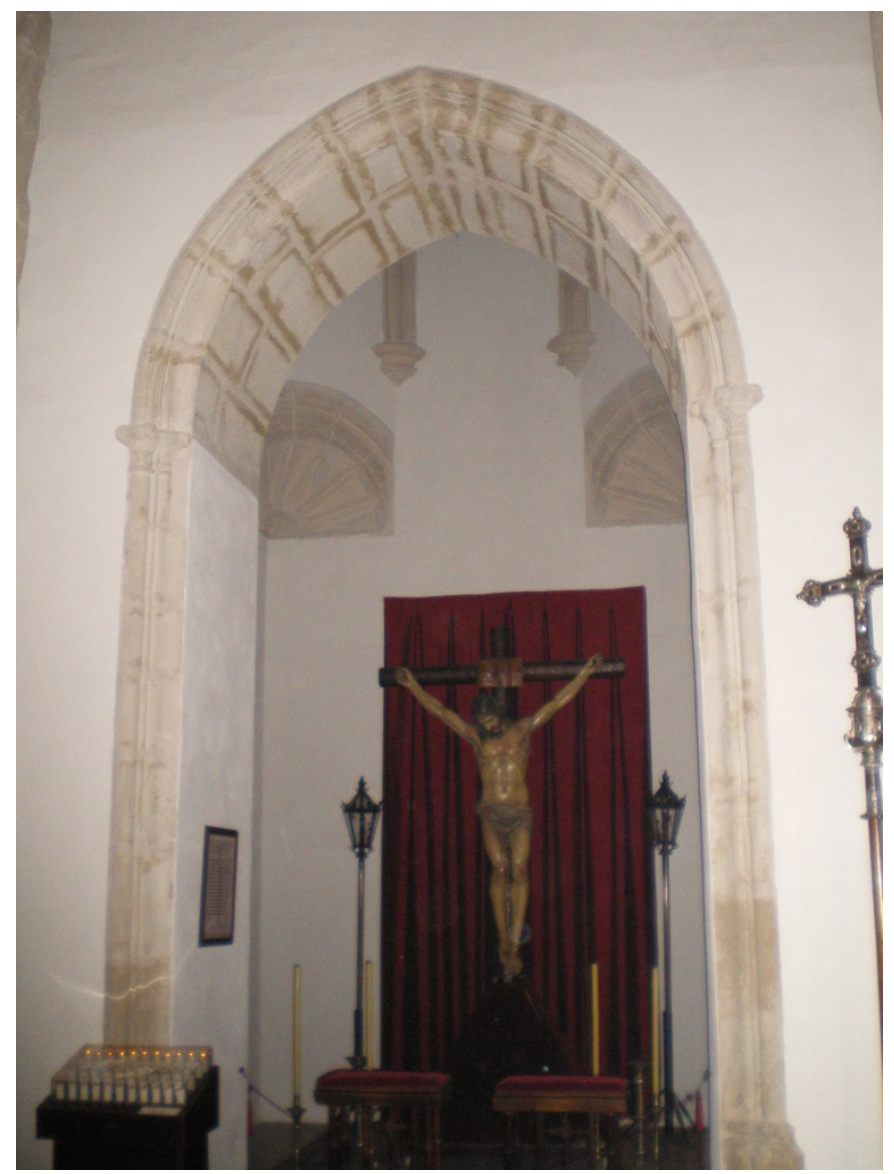

La participación del Rodrigo de Gibaja en su levantamiento es más que evidente. Era el maestro que llevaba la construcción del templo y el que se quedó con las contratas de casi todas las capillas particulares que hemos localizado. Lo que no está tan claro es de quién es el proyecto, si de Gibaja o más bien del artífice que trazó el templo en 1529, antes del gran seísmo.

Como el resto de las capillas abiertas a la girola, la del canónigo Francisco de Madrid se adapta al espacio existente entre dos contrafuertes, en concreto entre el primero y el segundo. Presenta planta cuadrangular y está cubierta con una sencilla y bonita bóveda de crucería.

El acceso a la misma presenta dos arcos apuntados, cuyas arquivoltas descansan en dos pequeñas semicolumnillas pareadas, y escalonadas, con diminutos capiteles de decoración vegetal. En los últimos coletazos del Gótico, momento en el que se trazó esta obra, los capiteles van haciéndose cada vez más pequeños y delicados hasta desaparecer.

Los capiteles siguen el modelo tardogótico más usual, el de ornamentación vegetal. Vaso decorado por un ramo de hojas, ceñido por correas al modo clásico, presentando en su centro una flor esquemática, recordando en su formato a una flor de lis. Idéntico elemento decorativo se repite en el equino, dónde las hojas laterales se enrollan dibujando volutas en los extremos.

Pensamos que el diseño de estas sencillas y discretas portadas pertenece a la traza de 1529, la anterior al seísmo de 1531, proyecto que giraba dentro de las líneas tardogóticas, en las que igualmente se diseñaron las pilastras entorchadas presentes en la girola, todo ello alejado del trazado presentado por el arquitecto castellano Alonso de Covarrubias.

La capilla del canónigo, de planta cuadrada, se ochava en altura mediante trompas cónicas, una solución constructiva que permite achaflanar las esquinas y superponer dos 


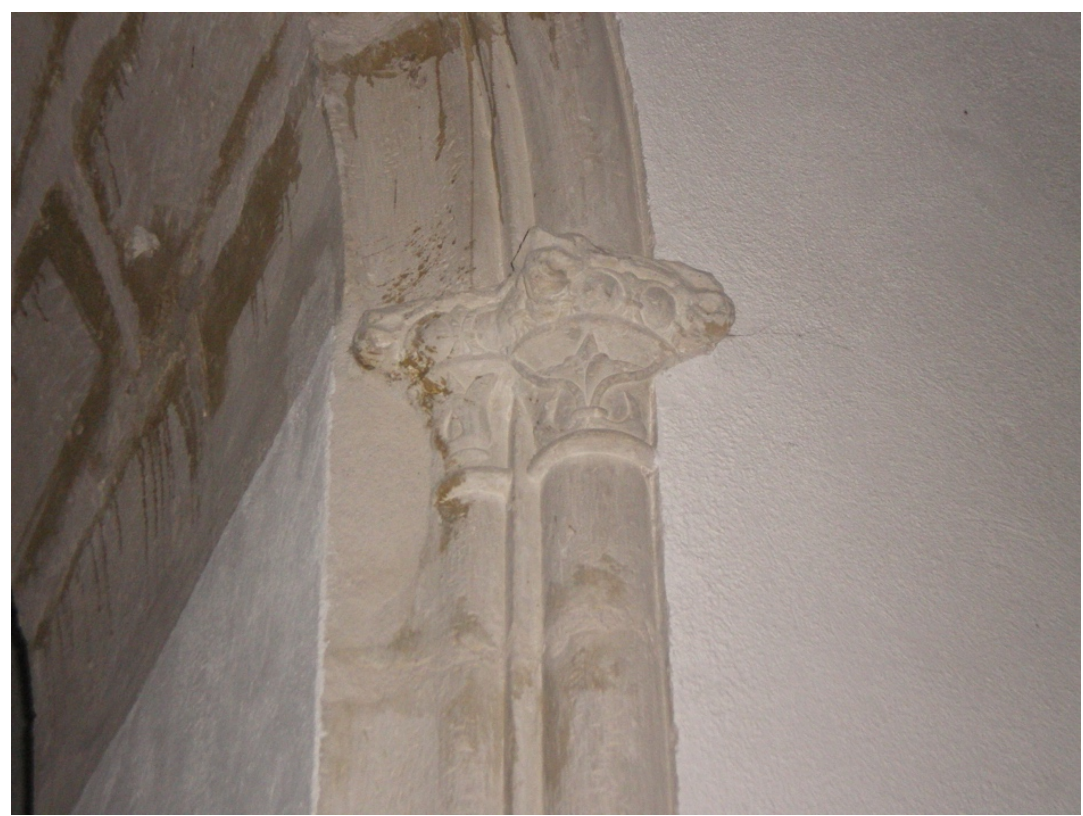

Fig. 3. Capiteles.

estructuras de diferente trazado geométrico, la de una bóveda sobre una base cuadrada. Las trompas, o bovedillas semicónicas, se utilizaron principalmente durante el Románico y el Gótico.

Se da la circunstancia de que en los reinos levantinos, de dónde pudieron llegar las influencias del primer proyecto de construcción de esta iglesia, tenemos varias construcciones dónde aparecen dos de los elementos principales presentes en la girola, y en las capillas asomadas a la misma, pilastras entorchadas y trompas, caso de una capilla del lado del evangelio de la catedral de Orihuela (Alicante) ${ }^{14}$.

Las trompas no se presentan lisas sino elegantemente decoradas. Arrancan de un semicírculo ornamentado con una de flor invertida. Su superficie se configura por siete casetones de formato triangular sin decoración. Con la llegada del Renacimiento el sistema decorativo de las cubiertas evolucionó, incorporando diseños de estirpe clásica. Fue entonces cuando comenzó a usarse sistemáticamente el casetón (un adorno geométrico cóncavo) y a utilizarse los catálogos del arquitecto y teórico Sebastiano Serlio, en concreto los del capítulo "Techos llanos de maderas y su decoración" del Libro IV de su tratado. En él se incluía un catálogo de sencillos modelos geométricos (casetones) que tuvo que resultar muy útil para los maestros españoles inclinados hacia las soluciones ornamentales renacentistas.

Quedan rematadas las trompas por una especie de moldura de arquitrabe perfilada, en un primer nivel, por una línea de rosario o de abalorio, en la que se suceden de forma rítmica una cuenta y un perlario de cuatro piezas.

En esta capilla se utiliza la solución más sencilla y recurrente para embeber los nervios en los muros, la de colocar ménsulas o repisas en las esquinas. Estas piezas (con carácter ornamental, aunque den otra apariencia) sobresalen del plano vertical y se presentan perfiladas con molduras decorativas, dos bandas de lengüetas, llamadas así por la similitud

${ }^{14}$ En el lado del Evangelio de la catedral de Orihuela se cierra una pequeña capilla de siglo XIV mediante cruceros radiales sobre planta en ochavo, apeada en trompas cónicas, de factura muy similar a la sacristía anterior de Valencia y a la capitular de la catedral de Segorbe que también emplea las trompas cónicas para pasar al ochavo. 


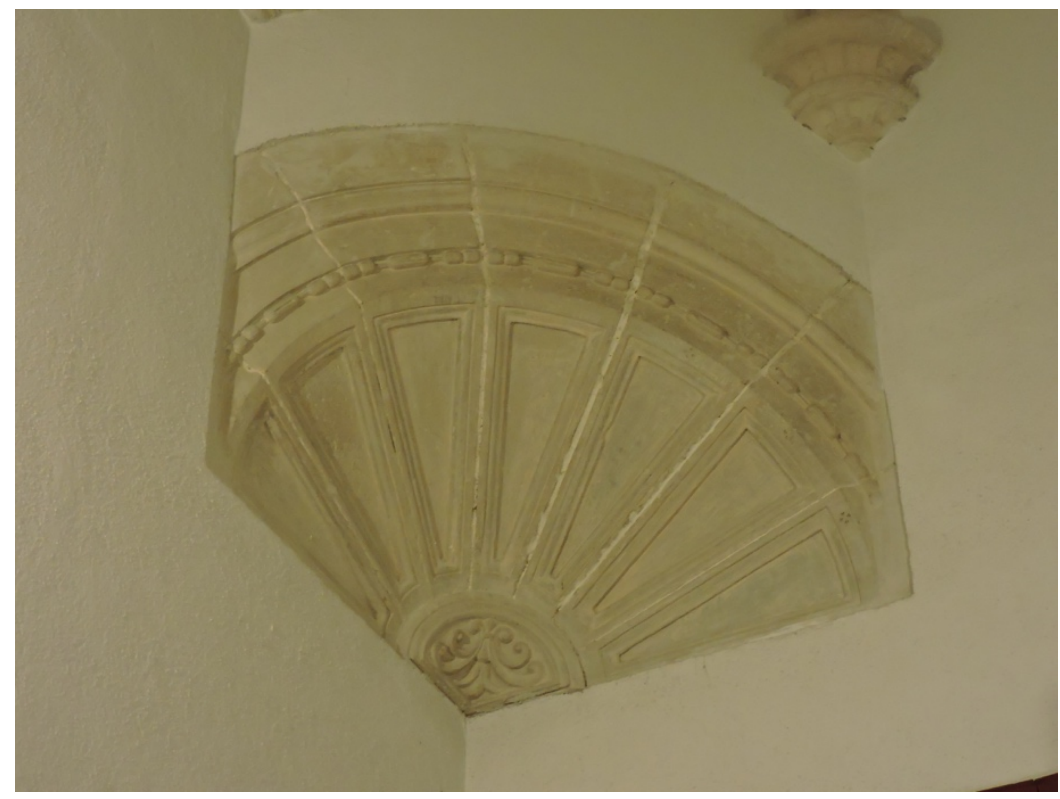

Fig. 4. Trompa.

de su forma con una lengua, siguiendo el mismo diseño de la capilla colateral, posiblemente construidas ambas en el mismo periodo, años treinta del siglo XVI.

Se cierra la capilla con una bonita bóveda de crucería propia de la arquitectura tardogótica, elemento habitual utilizado desde finales del siglo XV por muchos arquitectos, tipología que no desaparecerá de numerosas construcciones hispánicas del quinientos hasta una etapa muy avanzada. Se trata de una bóveda de crucería de siete claves, formando una estrella de seis puntas, diseño muy similar al de la capilla mayor de la iglesia de San Jerónimo de esta ciudad, levantada en 1535.

Las bóvedas estrelladas en general son una característica de la arquitectura traída del norte de Europa, un modelo utilizado por los maestros flamencos, borgoñones y alemanes. Eran consideradas más suntuosas cuando mayor era el número de claves. De las cinco capillas de la girola tres tienen cinco claves y dos siete, ésta que estamos viendo y la del abad Álvaro de la Torre.

Están ausentes en esta capilla las líneas de imposta, elemento clasicista que la acercaría más al mundo del Renacimiento, líneas que introducirá Alonso de Covarrubias por los muros perimetrales de toda la iglesia y Diego de Siloé en la capilla de los Araoz, la más destacada del templo.

La construcción de esta capilla sigue una de las soluciones más escogidas por parte la élite bastetana en la primera mitad del siglo XVI para sus panteones familiares, un modelo más cercano a lo antiguo, a la arquitectura tardogótica que lo nuevo, a la arquitectura la renacentista.

Cualquiera de las conjeturas aquí presentadas sobre su trazado está basada en deducciones y comparaciones estilísticas ante el vacío documental existente, moviéndonos en el terreno de la hipótesis. Aunque la documentación hallada no señala quién fue el artífice, todo apunta a que las obras las realizó Rodrigo de Gibaja, maestro mayor de la iglesia colegial, el artífice más demandado de Baza, de las poblaciones de su Abadía y de algunas localidades de reinos limítrofes. Dicho cantero, y su taller, llevaron a cabo el proyecto de Covarrubias para el templo y levantaron todas las capillas particulares conocidas en el mismo edificio, caso de la familia Araoz, diseño de Siloé. Este artista, de origen cántabro, llegó en la década de los años treinta al altiplano granadino, junto con otros maestros, entre los que se 


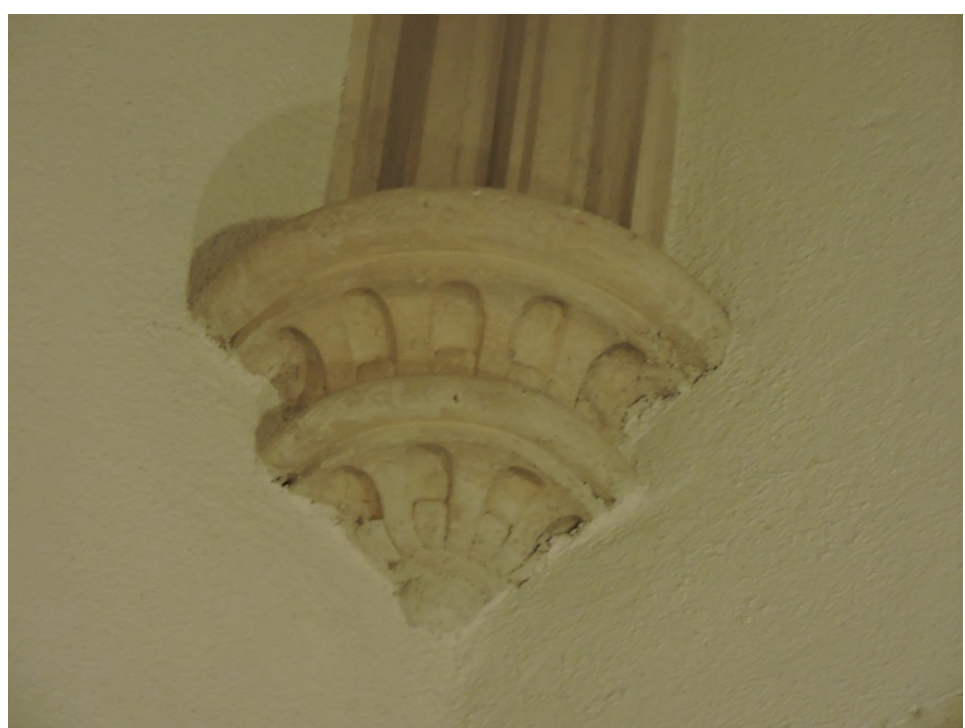

Fig. 5. Ménsula.

encontraban varios paisanos y familiares suyos, caso de su primo Juan García de Gibaja, llegando a ocupar el lugar dejado por los artífices más relevantes, caso del fallecido Pedro de Urrutía, uno de los más solicitados.

Según el profesor Rubio Lapaz estamos ante el máximo exponente de la actividad constructiva del quinientos en las altiplanicies granadinas, maestro que estaba desplegando una intensa labor durante las décadas centrales de la centuria. Cuando se levanta esta capilla el artífice se encontraba en el inicio de su prestigio profesional, encargándose de la mayoría de las obras relevantes de cantería de la urbe y de las comarcas de Baza y Huéscar en el altiplano granadino, siendo posteriormente requerido por poblaciones de reinos limítrofes, trabajando en Santa María de Quesada y en La Iruela (1537), localidades de la provincia de Jaén y en Cehegín (1548), en el Reino de Murcia ${ }^{15}$.

\section{El patrimonio mueble}

La capilla debió adornarse con un valioso patrimonio mueble y objetos litúrgicos de todo tipo, dotada de forma que quedara claro la valía personal del comitente y su papel en la jerarquía religiosa de la Abadía. En el testamento de Francisco de Madrid nada se precisó respecto al ornato con el que se dotaba a este espacio ${ }^{16}$.

El objeto principal de dicha capilla, desde la década de los treinta o cuarenta hasta la muerte del comitente, debió ser el Santísimo Sacramento y la magnífica custodia en la que éste se exponía, desconociéndose hoy en día casi todo sobre la misma. Debió ser una obra destacada de orfebrería de estilo plateresco que en la festividad del Corpus Christi posesionaba con la máxima solemnidad por las calles de la ciudad.

La obra, que debió desaparecer en los años de la ocupación francesa, tradicionalmente ha sido atribuida a Juan Ruiz "el Vandalino", uno de los más destacados orfebres andaluces de su época, artífice con escasas obras documentadas o atribuidas, caso las custodias de la catedral de Jaén y del convento de San Pablo de Sevilla.

Aunque la profesora Lázaro Damas afirma que las fuentes parroquiales conservadas no registran ninguna notica al respecto, ni relacionada con ella ni con su platero, hay una

\footnotetext{
${ }^{15}$ Rubio Lapaz, 1990: 135-162.

${ }^{16}$ El canónigo reservaba gran parte de su patrimonio y de las rentas del mismo para levantar y amueblar el convento e iglesia que mandaba fundar, en cuya capilla mayor ordenaba ser enterrado su cuerpo.
} 


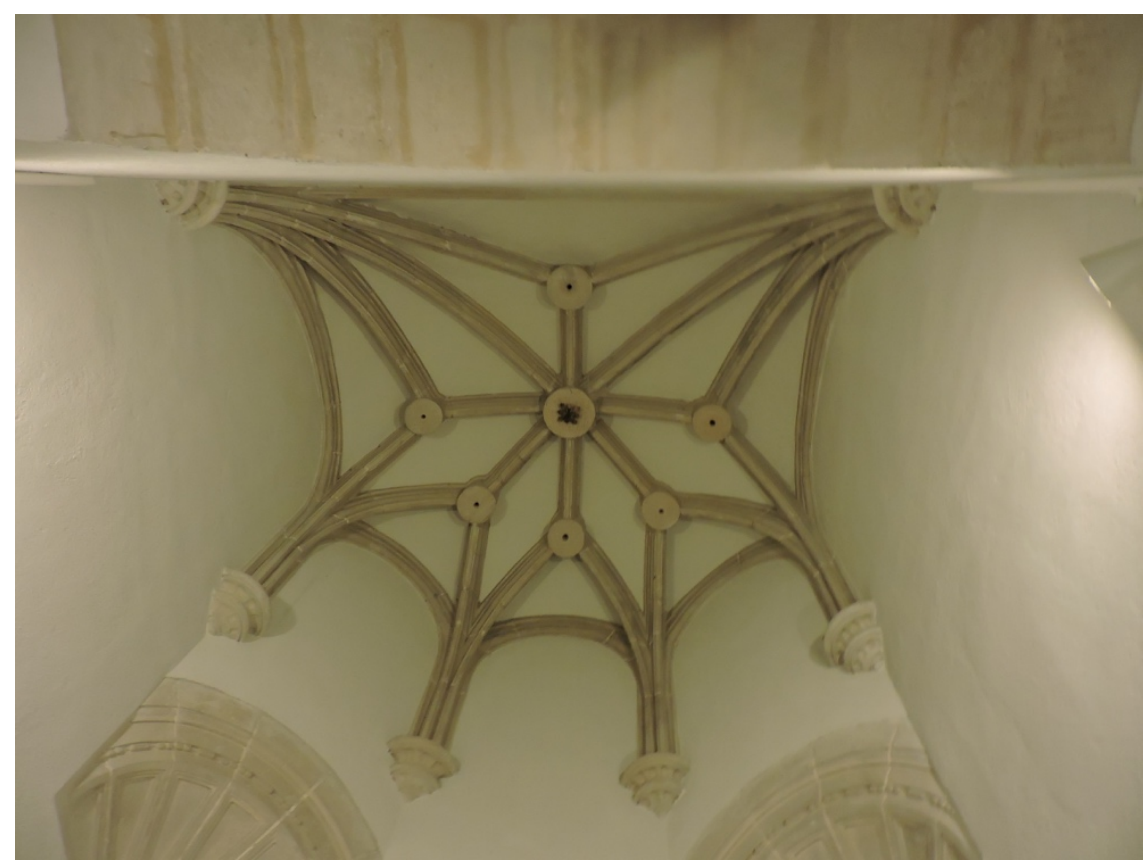

Fig. 6. Bóveda.

pequeña referencia indirecta del siglo XIX sobre su autoría, testimonio plasmado en las apreciaciones del viajero inglés Richard Ford (1830-1833), al anotar que la magnífica custodia fue obra de Juan Ruíz de Córdoba ${ }^{17}$. Probablemente esta pieza, junto con otros objetos artísticos de valor, fue saqueada por las tropas galas del mariscal Sebastiani, célebre por sus robos de obras de arte.

El afamado platero residió en Jaén en la década de los años treinta, momento de gran renovación artística en la ciudad de Baza, como consecuencia de la construcción de los templos parroquiales y primeros conventos y de una parte importante del patrimonio mueble de todos ellos, desaparecido tras el terrible terremoto de 1531. La iglesia de Santa María, para la que estaría destinada esta custodia, comenzó a ser levantada en 1534.

La conexión entre el platero y altos cargos religiosos relacionados con la Iglesia bastetana ha sido puesta de manifiesto por la profesora Lázaro. La posible vinculación pudo venir a través de altos cargos de la Abadía: un obispo de la diócesis de Guadix-Baza y un provisor y futuro abad: Martín Pérez de Ayala y Álvaro de la Torre. Ambos debieron conocer a Juan Ruiz y las obras que éste realizase para Jaén y para el área de la diócesis accitana en las décadas de los años treinta y especialmente cuarenta ${ }^{18}$.

Aunque no hemos localizado ningún documento que lo atestigüe, no descartamos que el canónigo colaborara o encargara dicha custodia, dado su gran patrimonio y su devoción al Santísimo Sacramento. Francisco de Madrid dejaba estipulado, en su testamento, donar 4 ducados anuales para proveer de aceite la lámpara del Santísimo Sacramento que había en la capilla que había comprado en la iglesia colegial. Si en algún momento se trasladase a otro lugar dejaba señalado que el dinero se emplease en comprar paño buriel y

\footnotetext{
17 López Burgos, 2000: 48.
}

18 Lázaro Damas, 1999: 175-194. El platero en su estancia en Jaén pudo estar relacionado con Martín Pérez de Ayala, residente en Granada como profesor desde 1532-1540, año este último en el que se trasladó a Jaén, coincidiendo su llegada a dicha ciudad con el último año de estancia del platero. En el año 1548 fue nombrado obispo de Guadix-Baza. En la década de 1540 destacar la presencia de don Álvaro de la Torre, deán de la catedral de Almería, y provisor de la iglesia de Baza, Huéscar y su partido. Este interesante personaje será el responsable, en última instancia, de la adjudicación de obras artísticas encargadas para la Abadía. 
se vistiese a varios pobres el día de Navidad. Igualmente legaba a la cofradía del Santísimo Sacramento 2 ducados y a la iglesia 10.000 maravedíes.

Desconocemos hoy en día el momento en el que la propiedad de la capilla pasó a los Méndez Pardo, una de las familias más poderosas de la Baza de la Edad Moderna. Debió realizarse en el último tercio del siglo XVI o ya en el siglo XVII ${ }^{19}$.

\section{La capilla definitiva en el convento de Santa Isabel}

Viendo que la fundación de un cenobio femenino con los fondos donados por el canónigo no era factible se decide desviarlos al convento de Santa Isabel. El obispo Juan Alonso de Moscoso tomaba la decisión tras tener presente que el legado del fallecido era insuficiente para la fundación y su mantenimiento sin aportación de dotes periódicas. Quizás pensara que con los ingresos anuales que dejaba el fundador las monjas iban a tener que depender, en gran medida, de las limosnas diarias de los habitantes de la ciudad, teniendo que salir de la clausura algunas de ellas para solicitarlas y/o realizando trabajos (tejidos, bordados...) para sobrevivir, pues la vida cotidiana en el interior del claustro de un cenobio con pocos ingresos no debía de tener nada de bucólica.

Pudo tener mucho que ver en la decisión final del prelado la oposición por parte del cabildo civil bastetano a la fundación de nuevos conventos. A mediados del siglo XVI los regidores bastetanos se oponían a la fundación de Santo Domingo, atendiendo a los muchos monasterios que ya existían y a la poca necesidad, que a su parecer, había de nuevas fundaciones.

La propuesta y decisión del obispado se concretaba en desviar el legado del canónigo a la creación de cuatro plazas para doncellas pobres que quisieran ingresar en el convento de Santa Isabel. A cambio la congregación debía ceder una capilla dónde se pudiese levantar un altar y retablo dedicado a Santa Ana, que habría de ser decorado con los ornamentos cedidos por el canónigo.

El 22 de diciembre de 1587 se presentaban las condiciones para levantar la capilla. Las obras fueron ejecutadas, y probablemente trazadas por los maestros de cantería Luis Antón y su hijo Jusepe Díaz, apareciendo aquí como maestro de albañilería. Los contratistas de la obra habían de aportar todos los materiales, trayendo la piedra de la cantera de la Ventilla.

Ambos artífices estaban destacando en el panorama arquitectónico local del último tercio del siglo XVI, tanto en obras religiosas como en edificaciones de carácter civil. En 1588, un año después del levantamiento de esta capilla, Luis Antón se quedaba con la construcción de la sacristía de San Jerónimo, con un presupuesto de 600 ducados. El 14 de abril de 1589 se le pagaba lo que le quedaba por recibir por la construcción de la capilla del canónigo, 43 ducados $^{20}$. Por esos años se estaba levantado la obra más relevante de la arquitectura civil bastetana del XVI, el ayuntamiento y su pórtico asomado a la plaza Mayor, obra en la que probablemente este cantero estuvo trabajando. El trazado de las arcadas y las columnas de este pórtico y las de la capilla tienen elementos en común. En 1594 tenemos a Jusepe Díaz, su hijo, trabajando en el levantamiento de las salas del cabildo municipal ${ }^{21}$.

Los maestros encargados de realizar la obra habrían de labrar una columna y tres semicolumnas de orden toscano, junto a las dovelas de los tres arcos levantados sobre las Fig.

19 Agradezco dicha información al historiador Juan Manuel Domene. A partir de ese momento la capilla pasó a ser la sede del Cristo de los Méndez, imagen de gran veneración en la localidad, siendo considerado un Cristo muy milagroso. A partir de ese periodo se colocó un retablo que permaneció hasta la Guerra Civil, siendo destruido como casi todo el patrimonio mueble religioso de esta ciudad. No sabemos si el primer propietario de este linaje fue el abad Antonio Méndez Pardo (1658-1572) o uno de sus antecesores. En su testamento, fechado en 1662, pide ser sepultado en la capilla del Santísimo Cristo, que estaba junto a la sacristía

20 Pago del dinero debido al maestro, A.P.Gr., Baza, Gabriel Jiménez, 1589, ff. 120v-121.

21 Tristán García, 2005: 137. El 2 septiembre se hablaba de la necesidad de cubrir dicha estancia antes de que llegasen las lluvias. 


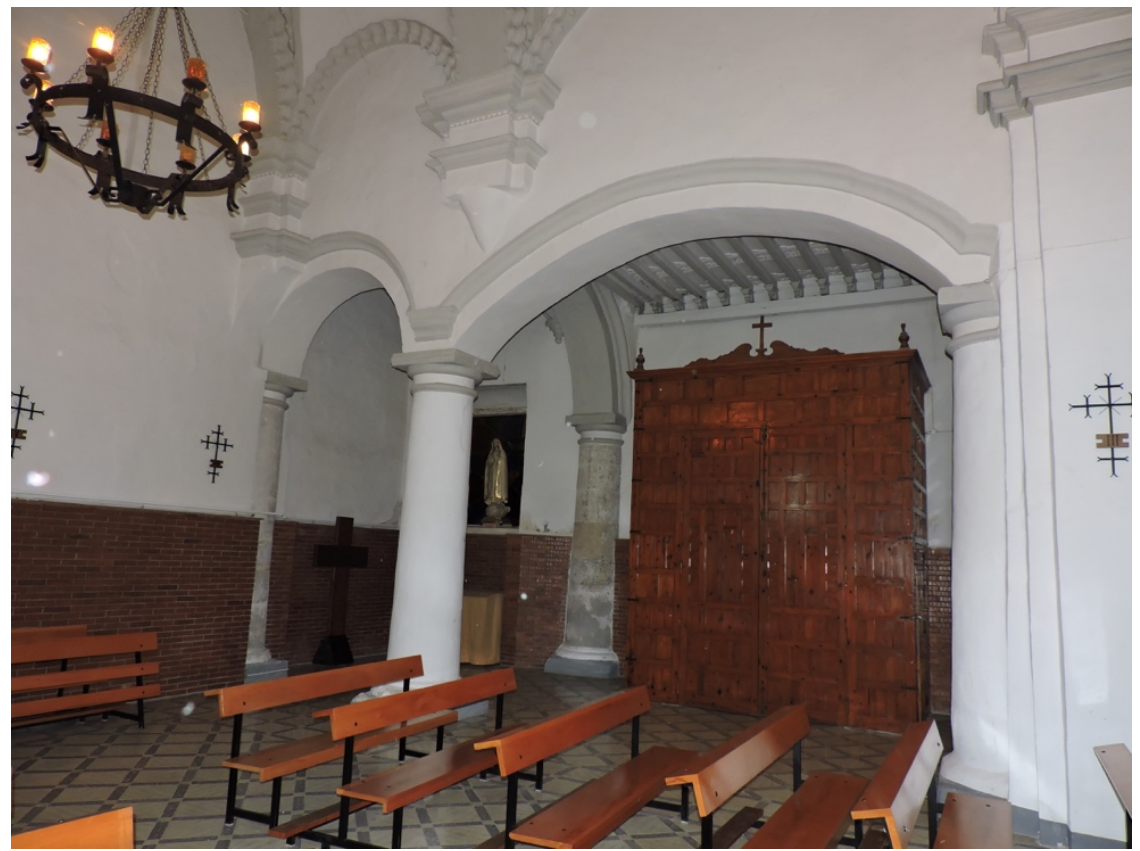

Fig. 7. Capilla definitiva del canónigo (hoy, entrada al templo). Iglesia de Santa Isabel de los Ángeles (actualmente Presentación).

mismas. La columna, con su basa y capitel, había de ser dos piezas, con cuatro palmos de grueso y del largo que diese la obra. Las tres semicolumnas, siguiendo el mismo trazado y orden, habían de estar adosadas en los muros que configuran la capilla y zona anexa.

La obra se habría de ejecutar en cuatro meses. En la primera mensualidad se aportarían 40 ducados y la piedra necesaria. Durante los tres meses restantes los encargados de los trabajos recibirán 10 ducados cada uno. Acabados los trabajos se nombrarían dos peritos, uno por parte del convento y otro por los maestros que realizaran la obra. Si por algún motivo no hubiese acuerdo se nombraría un tercero ${ }^{22}$.

La construcción de este espacio se realizaba fuera de los parámetros estilísticos de resto del templo, levantado tras el seísmo de 1531. La gran diferencia de esta capilla, con el resto, es su conexión con la nave principal, totalmente abierta, no existiendo muro de separación con la misma, utilizando sólo una columna en el centro y semicolumnas en los extremos ${ }^{23}$.

Esta intervención despliega dos espacios perfectamente delimitados. El primero de ellos, la capilla en si (hoy entrada al templo, con cancel incluido), presenta planta rectangular y está cubierto por un alfarje de un orden de vigas. Consta de quince jácenas apoyadas sobre canes de trazado gótico de tres lóbulos. La tablazón exhibe labor de menado con alfardones de perfil conopial y chillas de ocho puntas que recuerdan el alfarje del cuarto de la enfermería del convento.

${ }^{22}$ Condiciones de la obra a hacer en la capilla del canónigo Francisco de Madrid en la iglesia del convento de Santa Isabel de los Ángeles de Baza, A.P.Gr. Baza, Valentín Jiménez, 1587, ff. 496-498.

23 Siguiendo el modelo de iglesia semicolumnaria del templo de San Juan de esta ciudad. La actuación principal debió centrarse en sustituir el muro que separaba la capilla de la nave principal de la iglesia por columnas de corte clásico. Nada se dice en la contrata sobre las cubiertas, presentando esta intervención dos tipologías muy distintas, hecho que puede indicar que estamos ante una remodelación del tramo final de la única nave lateral del templo y de la planta baja del hueco de la torre, anexo a la misma, aprovechando los elementos conservados en buen estado, caso de las cubiertas. 


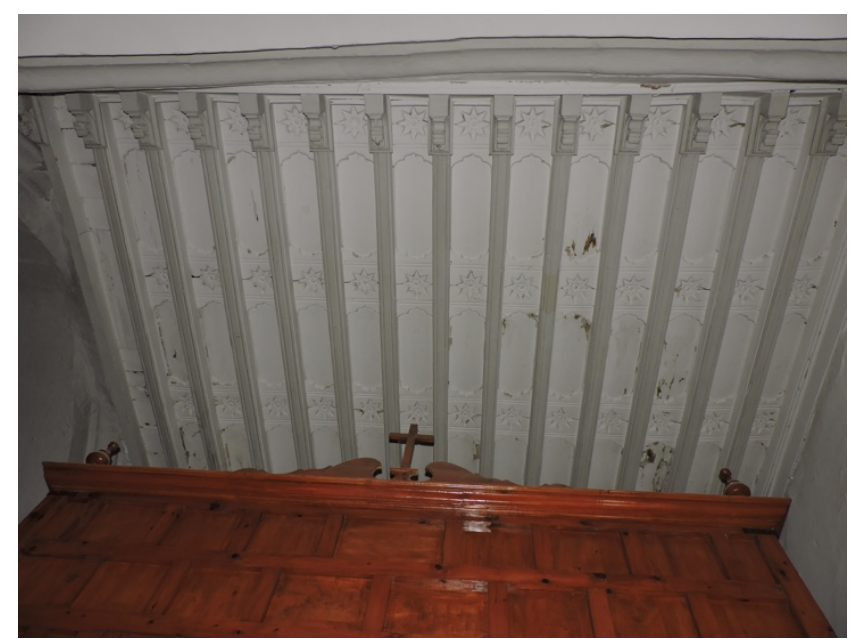

Fig. 8. Cubierta de la capilla del canónigo. Iglesia de Santa Isabel (hoy Presentación).

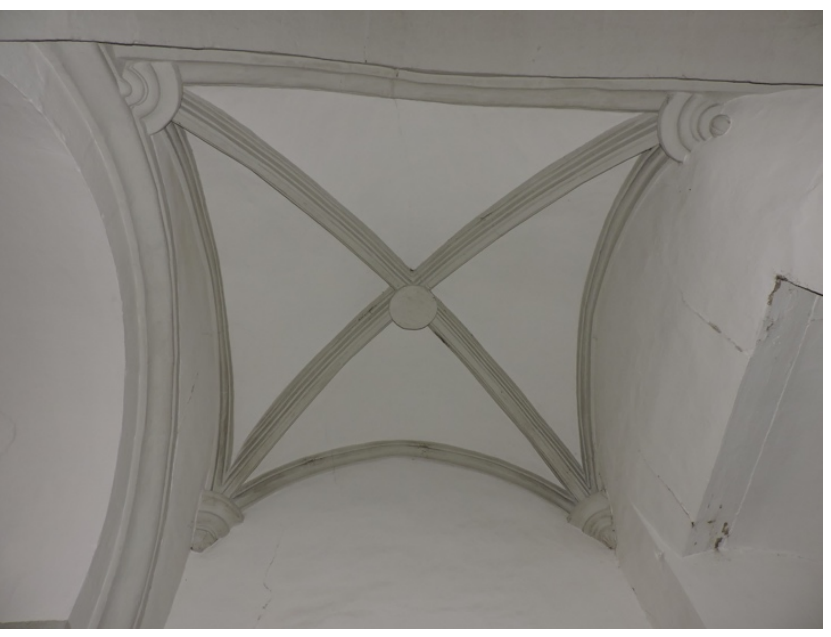

Fig. 9. Bóveda del espacio anexo a la capilla del canónigo. Iglesia de Santa Isabel (hoy Presentación).

El segundo espacio, ocupando el hueco de la torre, pudo desempeñar, desde el último tercio del siglo XVI hasta la remodelación del templo en la época barroca, la función de entrada principal a la iglesia ${ }^{24}$. El hueco dónde se ubica la ventana de iluminación parece coincidir con el de una puerta cegada en su parte inferior. Presenta una bóveda cuatripartita de crucería simple, la más adecuada para cubrir tramos cuadrados, formada por el cruce de dos arcos diagonales o cruceros que dividen la plementería en cuatro segmentos.

Tras la última remodelación del templo en el setecientos, realizada probablemente tras el gran terremoto de Lisboa (1755), se produce un revestimiento de la nave principal dentro del estilo Barroco y la imagen de las capillas asomadas a dicha nave, especialmente la del canónigo, queda algo desarticulada, al no encajar la ordenación de los elementos arquitectónicos del siglo XVI (especialmente las columnas) con las pilastras utilizadas para ordenar y distribuir los distintos tramos de la nave principal.

${ }^{24} \mathrm{O}$ tras la desamortización. 
Bibliografía

Bernard, V.: "La evolución del paisaje de Almería, siglos XVI-XIX". En: Relaciones 75, Escuela de Altos Estudios en Ciencias Sociales, París, (1998), 19, pp. 215-227.

Castillo Fernández, J.: "Negocios de familia. El perfil institucional y social de los mayordomos de propios del Reino de Granada (1492-1550)". En: Chronica Nova, 31, Granada, (2005), pp. 23-64.

Crespo Muñoz, F. J.: El notariado en Baza a comienzos de la Edad Moderna. Estudio y catálogo de los protocolos notariales (1516-1519). Tesis doctoral. Universidad de Granada. (2007).

Crespo Muñoz, F. J. y Luque Sánchez, E.: "La introducción de las escribanías castellana en la ciudad de Baza". En: Péndulo, 6, Baza, (2005), pp. 97-127.

Díaz López, J. P.: "La ganadería, un gran tema olvidado, el caso del norte del Reino". En: Crónica Nova, 25, Granada, (1998), pp. 227-247.

Lázaro Damas, M. S.: "Juan Ruíz el Vandalino y la desaparecida custodia de la catedral de Jaén”. En: Boletín del Instituto de Estudios Gienenses, 173, Jaén, (1999), pp.175-194.

Lázaro Damas, M. S: “Aportaciones documentales para el estudio de la iglesia mayor de Baza y sus primeros maestros de cantería". En: Iglesia y Sociedad en el Reino de Granada (ss. XVI-XVIII). Granada: Diputación y Universidad (2003), pp. 511-524.

López Burgos, M. A.: Por las rutas de Baza. Relatos de viajes (1809-1867). Melbourne: Australis Publishers. (2000).

Rubio Lapaz, J.:"Análisis de la obra de Rodrigo de Gibaja, arquitecto del siglo XVI". En: Cuadernos de Arte de la Universidad de Granada, 21, (1990), pp. 135-162.

Tristán García, F.: "Baza, 1525. (Un estudio de la sociedad a través de un padrón de cristianos viejos)”. En: Crónica Nova, 26, Granada, (1999), pp. 393-481.

Tristán García, F.: “Baza y Cervantes”. En: Péndulo 6, Baza, (2005), pp. 129-153. 